\title{
The Effect of Duration of Extreme Sports Involvement on the Perception of These Sports to be Extreme
}

\author{
Merve Ceylan
}

\begin{abstract}
The purpose of this study is to investigate whether the duration of extreme sports involvement has an effect on the perception of these sports to be extreme. In line with this objective, 6 extreme sportsmen, selected by judgement sampling method and participated in different extreme sports, were involved in this study. In the study, the interview method, which is a qualitative data collection method and based on verbal communication, was used and the sound recording of dialogues was made. Consequently, it is seen that as the time spent on extreme sports increases, so does the gain in experience, so, extreme sportsmen avoid taking unnecessary risks, and that a decrease in the risk of accident in these sports cause people not to perceive them as extreme as in the first day, and seek for new extreme sports.
\end{abstract}

Keywords: Extreme Sport, Perception of Extreme, Experience

\section{Introduction}

Modern lifestyles and contemporary sporting trends have led to a noticeable increase in the involvement in extreme sports and adventure activities which are increasingly preferred by people, especially young people (Şimşek, 2010).

Young people are permanently involved in extreme sports, even though many of these sporsts are of high risk by nature. When young people do not deem a sport activity as challenging enough, they lose their interest in this sport and feel strange from that. Risk-free activities deprive young people of testing themselves against motivating and exciting physical challenges. Risk taking is important for the development of young people' risk management skills and mental health. Avoiding boredom, developing test skills, overcoming fears motivate many adventure sport sportsmen, and young people to reach their objectives. Risk is a fact of life. (The New York Times Upfront Magazine 2016)

Although it is considered meaningless and even reckless to take unnecessary risk in society, it appears that there is an acceptable increase in being involved in risky sports (Lupton, 1999). As a result of a questionnaire regarding sports involvement, made between the years of 1978-2000 in the United States, it was seen that the involvement in primary sports branches (such as tennis, basketball, baseball and golf ) increased by 1.8 percent on average; quite strikingly, the involvement in alternative sports (such as rock climbing, skiing and mountain biking) increased by 244.7 percent in the same period. (Hennigs, Hallmann, 2014). Nevertheless, the limited number of studies have been done on these popular sports. Petrecca and Bennett et. al. stated that extreme sports have increasingly become widespread as a popular individualist sports branch. Others have gone a step further and defined extreme sports as a revolution in the world of sport (Puchan, 2004).

Extreme sports activities are more risky than other sports by nature. Extreme sports include those such as paragliding, rock climbing, mountain bike landing, kiteboard, snowboard, skiing, free diving, windsurfing, hangglider.
These sports usually require speed, highness, advanced physical effort, balance, quick decision making and important special equipments. In Europe, the death was 40 times higher in mountain sports than in boxing; 70 times higher in scuba diving than in rugby; and 190 times higher in hangglider than in football (Collard, Oboeuf 2012). (Collard, Oboeuf 2012). When the medical analysis of nonfatal sports accidents is examined, it is seen that the rate of hospitalisation due to the reasons concerning skiing and parachute is over 30\% (Duval 1996). This rate is $12 \%$ for gymnastics, $7 \%$ for team sports and $6 \%$ for competitive swimming (Elias 1986).

The investigations regarding the people involved in risky sports show that these people have two distinctive personality traits. These traits are excitement seeking, and high level self sufficiency in general. These two characteristics appear to be the main factors influencing the involvement in risky sports and recreational activities. However, when the literature was reviewed, no study was found on the investigation of whether the duration of extreme sports involvement has any effect on the perception of these sports to be extreme.

In this study, it will be investigated that whether the extreme sports perception of people who are involved in extreme sports change according to the duration of extreme sports involvement. In line with this objective, the answers of following questions that will be asked to the people involved in extreme sports will be sought for:

1) What are the factors that motivate you to do extreme sports?

2) Do you find extreme sport / sports as extreme as in the first day?

3) If your answer is "no" why?

\section{Method}

In line with the objective of the study, 6 extreme sportsmen who have participated in different extreme sports, and from different nations, were interviewed. 


\section{International Journal of Science and Research (IJSR) \\ ISSN (Online): 2319-7064}

Index Copernicus Value (2016): 79.57 | Impact Factor (2015): 6.391

In the study, the interview method, which is a qualitative data collection method and based on verbal communication, was used, and the sound recording of dialogues was made. In the interview method, what the participants say is important, not the numbers, in being reported of the data (Creswell, 1998).Therefore, while analyzing and reporting, the spoken language was noted to remain as it was. The judgement sampling method was used in the selection of participants of the study. In this sampling method, the researcher chooses such a sample according to his or her judgment that he/she believes that it is the best one for an investigation to be made in his/her field of study

\section{Findings}

1) Austine (Argentina, 26 years old, does kiteboarding for 2 years); I think the most important factor that makes a sport extreme is the risk of serious injury or even death. Extreme sport means to challenge to nature's conditions, and compete with it. Therefore, it is not clear what and when nature will offer you. The thing that I like most in an extreme sport is to push my limits. The thing that makes me happy most in kiteboarding is to compete with both nature and myself. You set off on water, and you don't know what will you confront with... I still feel the same excitement in every kiteboarding...

2) Alex ( Brazil, 31 years old, does snowboarding for 5 years, and mountain bike landing for 2 years)... - The main factor that motivates me to do extreme sports is the excitement and to seek for new things... Everyone thinks extreme sport as competing with nature, but think it is to move in harmony with nature. First of all, you can not compete with nature, only move in accordance with the conditions it offers... It is very important what you shouldn't do rather than what you should do in doing extreme sports. If you choose materials that are suitable for weather conditions, you will reduce the risk. The more time you spend on a sport, the sooner you learn how to control the risk. Therefore, I don't find the sports I do as extreme as they used to be.

3) Hannah ( England, 31 years old, does free diving for 2 years); to struggle to survive under conditions I can not control, and have a close brush with death at any moment increase my attachment to life, that's why I do free diving... At the end of each diving, I realize that even though I can't notice at that moment, I push my limits more than previous diving. Although this sometimes scares me, it does not reduce my desire to dive at all... Every diving still excites me as much as my first diving, and I do not think I will lose this excitement at all.

4) Mathilda (France, 29 years old, does skiing for 12 years, paragliding for 7 years, hangglider for 3years, and kiteboarding for 1 year); if you feel fear and excitement simultaneously, this indicates that you do an extreme sport. I do not think of anything else while I'm doing sport, which helps me to get away from all my stresses and anxieties and to relieve. I have a stressful job, but after doing an extreme sport, I feel refreshed myself, which prevents me from being tired of my job... After doing the sports for a long time, I learn to which difficulties I can confront, accordingly, I take precautions and take the risk under control, which reduces the excitement. For this reason, every 2-3 years, I seek for a new extreme sport.

5) Scoth ( USA, 26 years old, does stream skiing for 4 years and hangglider for 2 years); I like to push my limits, doing extreme sport helps me to relax both physically and emotionally. It increases my self confidence. It also allows me to be more popular in my social circle... I feel to move on a thin line between life and death every time when I do hangglider, and I love this feeling. I like the discipline of struggling with nature and adapting to the conditions when I do stream skiing, because nature does not forgive mistakes. I still find extreme the sports that I do, because I learn something new every time, which leads me to feel more excited.

6) Deniz ( Turkey, 41 years old, does windsurfing for 23 years, kiteboarding for 15 years, stream skiing for 12 years, snowboarding for 8 years); In my opinion, in order for a sport to be deemed extreme, it should include uncontrollable conditions, and the risk of serious injury... I started to do extreme sports to seek for adventure and excitement... After I have done a sport for a long time until it didn't give me excitement any more, I started to seek for a new sport. This has continued in this way, and I currently can do many extreme sports. I've been doing some of them for a long time, and I've left some of them after a few trials. ... For example, windsurfing is as easy as breathing for me, that's why I do not find it as risky as it used to be. But, I still find snowboarding a bit more risky. I think, the risk factor is getting smaller as you get more experience.

\section{Discussion and Conclusion}

When the answers given by the participants are examined, it is seen that the factors that motivate participants to do extreme sports usually are; searching for excitement and adventure, pushing the limits, avoid stress and anxiety, physically and spiritually relief, sense of struggle with nature, and popularity. Taking risk voluntarily in extreme sports, involvement in activities that are perceived as dangerous, but that can be chosen intentionally and through election is defined as "a behavior including individuality" (Stelmach, 2004).

Milne and McDonald (1999) are the first researchers who revealed the motivation of sports consumption. They talked about thirteen motivation that are effective on the involvement in sports, in the scale they developed. These thirteen motivation are blow off steam, mastership, aesthetics, self realization, self confidence, value development, social relief, belonging, competition, aggression, risk taking, success, physical fitness. A study that investigated extreme sports motivation identified risk as one of the most motivating factors. Other major motivating factors identified are entertainment, avoid stress, experience,, adventure, and being in touch with nature. Trail and James (2001) hypothesized that there are nine motivators to follow up sports. These nine motivators are achivement, acquisition of knowledge, aesthetics, drama / eustress, escape, family, physical attractiveness of participant, quality of participant's physical abilities, and social interaction.

\section{Volume 6 Issue 12, December 2017}




\section{International Journal of Science and Research (IJSR) \\ ISSN (Online): 2319-7064}

Index Copernicus Value (2016): 79.57 | Impact Factor (2015): 6.391

It was determined in a study in which the role of perceived benefits in sports involvement was investigated that the primary motivating factors in some extreme sports such as skydiving, hang gliding, parachuting are seeking for excitement and adventure. It was also stated that the reason why individuals prefer extreme sports is that these sports offer opportunities to keep away from the daily routine life style. Rinehart and Sydnor (2003) suggest that extreme sports appeal to young people more than traditional sports, and that the reason for this is to offer them more opportunity to show their performance to other people.

The investigations regarding the people involved in risky sports show that these people have two distinctive personality traits. Ceylan et al. (2016) defined these traits as excitement and adventure seeking, and high level self sufficiency in general. These two characteristics appear to be the main factors influencing involvement in risky sports and in recreational activities. The participants also expressed that in order for a sport to be deemed extreme, it should include serious injury and death risks, the struggle with noncontrollable natural conditions and fear factors. According to the participants' answers to the question of whether they still find the sport they do extreme; the risk factor decreases in case that the spend time on doing sport increases, and that material, suitable for weather condition, is selected.

Contrary to society's point of view, Pain and Pain (2005) stated that extreme sports require permanent attention, high level of training and preparation, and above all, discipline and control, and that most of the participants are aware of their strengths and limitations against clear threats. A comprehensive research's findings on mountaineer show that individuals don't want to put their life in danger going beyond their personal talents. From this point of view, it is possible to say that the individuals who spend a lot of time doing extreme sports are aware of their limitations due to the experience they gained, which decreases the risk of sports involvement.

Slanger and Rudestam (1997) stated that their study's extreme sport participants didn't think that these activities are arranged to raise the risk. The studies also suggest that the people involved in extreme sports don't tend to look for uncertainty or uncontrollability. Chelsea et al. (1993) revealed in their study that experienced extreme sports participants prefer to postpone their activity in case that they feel conditions will push their limits, and get out of their control.

Many forms of risk taking constitute the most important feature of extreme sporting activities. Taking the perceived risks does not mean running on the threats that are most likely to occur in nature. Therefore, the management of existing risks can facilitate the prevention of accidents or adverse events that may occur in extreme sports (Brown, 1998).

As a result; in the light of the answers given by the participants; it is possible to say that experience is an important factor in the risk perception. It appears that as the time spent for extreme sports increases, the experience gained increases as well and thus, extreme sportsmen avoid taking unnecessary risks. It also appears that in the case of a decrease in the risk of an accident, sport is not perceived as extreme as in the first day, and as a result, people start to seek for a new extreme sport.

\section{References}

[1] Celsi, R.L., Rose, R.L., \& Leigh, T.W. (1993). An Exploration of factors influencing the likelihood of participation and the effects of experience. Leisure Studies, 22, 239-253

[2] Ceylan.,M., Altıparmak.,E., Akçakoyun.,F., 2016. The analysis of the relationship between personality traits of extreme athletes and sports consumption motives. International Journal of Human Sciences

[3] Clough, P., Houge Mackenzie, S., Mallabon, L., Brymer, E. 2016. Adventurous Physical Activity Environments: A Mainstream Intervention for Mental Health. Sports Medicine 46:7, 963-968.

[4] Collard, L., Oboeuf, A. (2012). Do dangerous sports specialists play more dangerously? An experimental study on sample selection. Journal of Risk Research, Pages 39-50 | Received 27 Jul 2011, Accepted 21 May 2012, Published online: 12 Sep 2012

[5] Creswell, J.W. (1998). Qualitative Inquiry and Research Design: Choosing Among Five Traditions. Thousand Oaks, California: Sage.

[6] Duval, C. 1996. European Home and Leisure Accident Surveillance System (EHLASS), Paris: CITI2.

[7] Elias, N. 1986. Quest for excitement, Sport and leisure in the civilizing process. Oxford: Basil Blackwell.

[8] Hennigs, B. Hallmann, K. 2014. A motivation-based segmentation study of kitesurfers and windsurfers. Managing Leisure 1-18.

[9] Lupton, D. 1999. Risk and Sociocultural Theory: New Directions and Perspectives. Cambridge University Press, 1-25

[10] Milne, G.R. ve Mcdonald, M.A. (1999) "Sport Marketing: Managing the Exchange Process" Milne et al (eds.) Motivation of sport Consumer, Sudbury, MA,Jones and Bartlett Publisher

[11]Pain, M.T.G., \& Pain, M.A., (2005) Essay: Risk Taking in Sport. The Lancet, 366(1), S:33-34

[12] Puchan, H. (2004). Living 'extreme': Adventure sports, media and commercialisation, Vol. 9, 2 171-178 Journal of Communication Management

[13] Slanger, E. \& Rudestam, K.E. (1997). Motivation and Disinhibition in high risk sports: Senseation seeking and self efficacy. Journal of Research in Personality, 31, 355-374

[14] Stelmack, R.M.; (Ed.), "On the Psychobiology of Personality”, Elsevier, London, England (2004), pp. 1728

[15] Şimşek, K.Y., "Türk Ekstrem Sporcuları İçin Spor Tüketim Güdüsü Ölçeğinin Güvenirlik ve Geçerlik Çalışması", Celal Bayar Üniversitesi Beden Eğitimi ve Spor Bilimleri Dergis, 5(3):97-106, 2010

[16] The NewYork Times Upfront Magazine 2016, February, 8, pages: 22-24

\section{Volume 6 Issue 12, December 2017}

